\title{
Congener-specific determination of ultratrace levels of chlorinated and brominated polycyclic aromatic hydrocarbons in atmosphere and industrial stack gas by isotopic dilution gas chromatography/high resolution mass spectrometry method
}

\author{
Rong Jin ${ }^{\mathrm{a}, \mathrm{b}}$, Guorui Liu ${ }^{\mathrm{a}, \mathrm{b}, *}$, Minghui Zheng ${ }^{\mathrm{a}, \mathrm{b}}$, Heidelore Fiedler $^{\mathrm{c}}$, Xiaoxu Jiang $^{\mathrm{a}, \mathrm{b}, \mathrm{d}}$, \\ Lili Yang ${ }^{\mathrm{a}, \mathrm{b}}$, Xiaolin $\mathrm{Wu}^{\mathrm{a}, \mathrm{b}}$, Yang $\mathrm{Xu}^{\mathrm{a}, \mathrm{b}}$ \\ a State Key Laboratory of Environmental Chemistry and Ecotoxicology, Research Center for Eco-Environmental Sciences, Chinese Academy of Sciences, P.O. \\ Box 2871, Beijing 100085, China \\ ${ }^{\mathrm{b}}$ University of Chinese Academy of Sciences, Beijing 100049, China \\ ${ }^{c}$ MTM Research Centre, School of Science and Technology, Örebro University, SE-701 82 Örebro, Sweden \\ d China National Environmental Monitoring Centre, Beijing 100012, China
}

\section{A R T I C L E I N F O}

\section{Article history:}

Received 24 April 2017

Received in revised form 7 June 2017

Accepted 9 June 2017

Available online 10 June 2017

\section{Keywords:}

Isotopic dilution method

${ }^{13} \mathrm{C}$ labelled compounds

Chlorinated PAHs

Brominated PAHs

Atmosphere

Stack gas

\begin{abstract}
A B S T R A C T
Isotopic dilution gas chromatography combined with high resolution mass spectrometry (GC/HRMS) has overwhelming advantages with respect to the accuracy of congener-specific ultratrace analysis of complex persistent organic pollutants (POPs) in environmental matrices. However, an isotopic dilution GC/HRMS method for analysis of chlorinated and brominated polycyclic aromatic hydrocarbons ( $\mathrm{Cl}-\mathrm{PAHs}$ and $\mathrm{Br}$-PAHs) using ${ }^{13} \mathrm{C}$-labelled congeners as internal standards has not been established. In this study, a method for identification and quantification of 38 congeners of $\mathrm{Cl}-\mathrm{PAHs}$ and $\mathrm{Br}$-PAHs in atmosphere and stack gas samples from waste incinerators was developed using the isotopic dilution GC/HRMS technique. The instrumental detection limits of the GC/HRMS method ranged from $0.2 \mathrm{pg}$ to $1.8 \mathrm{pg}$ for $\mathrm{Cl}-\mathrm{PAH}$ congeners, and $0.7 \mathrm{pg}$ to $2.7 \mathrm{pg}$ for $\mathrm{Br}$-PAH congeners, which were about three orders of magnitude lower than those of the GC/quadrupole MS method. This new method developed was also the first to enable determination of $\mathrm{Cl}-\mathrm{PAH}$ and $\mathrm{Br}$-PAH homologs comprising congeners with the same molecular skeleton and chlorine or bromine substitution numbers. Among the detected congeners, seven $\mathrm{Cl}-\mathrm{PAH}$ congeners and thirteen Br-PAH congeners that were abundant in the atmosphere and stack gases released from waste incinerators were firstly detected in real samples and reported using the established isotopic dilution GC/HRMS method. The developed isotopic dilution GC/HRMS is significant and needed for better studying the environmental behavior and health risk of $\mathrm{Cl}-\mathrm{PAHs}$ and $\mathrm{Br}-\mathrm{PAHs}$.
\end{abstract}

(C) 2017 Elsevier B.V. All rights reserved.

\section{Introduction}

Chlorinated and brominated polycyclic aromatic hydrocarbons (Cl-PAHs and Br-PAHs) are the halogenated analogues of their parent compounds (PAHs). Cl-PAH and Br-PAH congeners can exert toxic effects by binding to aryl hydrocarbon receptor (AhR), which is similar to that of the most well-known polychlorinated dibenzop-dioxins and dibenzofurans (PCDD/Fs) [1]. Toxicological studies

\footnotetext{
* Corresponding author at: State Key Laboratory of Environmental Chemistry and Ecotoxicology, Research Center for Eco-Environmental Sciences, Chinese Academy of Sciences, P.O. Box 2871, Beijing 100085, China.

E-mail address: grliu@rcees.ac.cn (G. Liu).
}

have shown that the toxicities of some congeners of Cl-PAHs and $\mathrm{Br}$-PAHs were higher than their parent compounds [1-3]. For the low molecular weight $\mathrm{Cl}-\mathrm{PAHs}$ (three ring and fluoranthene derivatives), the AhR-mediated activities were elevated with the substituted chlorine atoms numbers [4]. The occurrence of a few congeners of $\mathrm{Cl}$-PAHs and $\mathrm{Br}$-PAHs in various environmental matrices including air fine particles, fly ash from waste incinerators, tap water, and snow has been reported [4-10]. Accordingly, the environmental and health risks posed by $\mathrm{Cl}$-PAHs and $\mathrm{Br}$-PAHs have attracted increased attention in recent years.

Currently, there are few publications describing procedures for the analysis of Cl-PAHs and Br-PAHs in complex environmental matrices. Gas chromatography coupled to quadrupole mass spectrometry (GC/quadrupole MS) is the preferred instrumental 
combination that has been used for analyzing $\mathrm{Cl}$-PAHs and $\mathrm{Br}$ PAHs to date [11-17]. Wang et al. established a GC/quadrupole MS method by using an external standard technique with the goal of screening several Cl-PAH congeners formed during combustion of polyvinylchloride $[14,15]$. This method requires multiple essential steps including sample extractions, cleanups and enrichments to be conducted prior to instrumental analysis in complex environmental samples, which can lead to losses of target compounds. Therefore, such a GC/quadrupole MS method employing the external standard technique is not sufficiently robust and cannot be recommended for congener-specific analysis of Cl-PAHs in complex matrices. Another publication by Wang et al. used pressurized liquid extraction and GC/quadrupole MS for determination of Cl-PAHs in soil and water samples $[12,13]$. However, only eight congeners of Cl-PAHs could be quantified. Many congeners such as high chlorinated congeners of Cl-PAHs could not be determined by this method although their potential presence high contents in the environment. The selectivity of GC/quadrupole MS methods does not seem to be sufficient for the simultaneous identification and quantification of much more congeners of $\mathrm{Cl}-\mathrm{PAHs}$ and $\mathrm{Br}$-PAHs present in environmental samples. A comprehensive two-dimensional GC/time of flight mass spectrometry (GC $\times$ GC/TOF-MS) method has also been employed to separate complex PAH derivatives, including Cl-PAHs $[18,19]$. Better separation of these contaminants can be achieved by using the advantages of GC $\times$ GC over simple/linear GC. TOF-MS provides an advantage by screening chemicals using the full scan mode of TOF-MS. However, the sensitivity of TOF-MS is not as good as high resolution mass spectrometry (HRMS; defined as magnetic sector field instrument) in selected ion monitoring (SIM) mode.

Isotopic dilution GC combined with high resolution mass spectrometry (GC/HRMS) is widely recognized as the most powerful tool for congener-specific analysis of ultratrace persistent organic pollutants (POPs) in environmental matrices [20-23]. The use of ${ }^{13} \mathrm{C}$-labelled standards is laid down in the major analytical methods for PCDD/Fs, polychlorinated biphenyls (PCB) or polybrominated diphenylethers (PBDE) such as EPA 1613, EN 1948, EPA 1668 or EPA 1614 [24-27]. Isotopic dilution GC/HRMS still has many advantages over other analytical techniques especially for the analysis of ultratrace concentrations of POPs in complex environmental matrices for several reasons. Specifically, the resolution of HRMS can be easily adjusted to over 10,000, which could greatly improve the selectivity for specific congener determination compared with that of quadrupole MS with limited resolution. The addition of ${ }^{13} \mathrm{C}$ labelled congeners into the samples before pretreatment could be used to calibrate the loss of corresponding native congeners during the extraction and cleanup procedure, ensuring accurate results despite multiple extraction, cleanup and concentration steps prior to instrumental detection. For example, the methods (US EPA 1613B, US EPA 1668 C and US EPA 1614) for identification and quantification of POPs including PCDD/Fs, PCBs and PBDEs at trace levels in complex environmental samples all adopted the isotopic dilution GC/HRMS technique using ${ }^{13} \mathrm{C}$-labelled congeners as internal standards. However, no isotopic dilution GC/HRMS method for congener-specific analysis of $\mathrm{Cl}-\mathrm{PAHs}$ and $\mathrm{Br}$-PAHs using ${ }^{13} \mathrm{C}$ labelled congeners as internal standards has been established to date.

The application of GC/HRMS to investigate the occurrence and profiles of Cl-PAHs and Br-PAHs in urban air and airborne particles has also been reported in previous studies $[2,8]$. However, only several $d$-labelled PAH congeners, such as fluanthene- $d_{10}$ and perylene- $d_{12}$ et al., were used as internal standards. Application of a few $d$-labelled PAH congeners as internal standards might not be sufficient for accurate identification and quantification of the recoveries of $\mathrm{Cl}$-PAHs and $\mathrm{Br}$-PAHs after multiple pre-treatment steps owing to the different structures and properties of $\mathrm{PAH}$ species from those of Cl-PAHs and Br-PAHs. Despite advances in methods used to analyze Cl-PAHs and Br-PAHs in recent years, they are still insufficient for accurate congener-specific qualification and quantification of $\mathrm{Cl}-\mathrm{PAHs}$ and $\mathrm{Br}$-PAHs at the same time.

Homolog concentrations and distributions could provide important information for exploring the environmental characteristics or formation mechanisms of POPs unintentionally produced during industrial thermal processes. For example, methods for quantifying homolog concentrations of PCDD/Fs and PCBs using GC/HRMS with ${ }^{13} \mathrm{C}$-labelled congeners as internal standards are available [23,28-32]. Moreover, it is meaningful to quantify the homolog concentrations with the goal of providing a full spectrum of information regarding the environmental and human risk of total Cl-PAHs and Br-PAHs in the environment. However, no method for determination of the homolog concentrations of $\mathrm{Cl}$-PAHs and $\mathrm{Br}$-PAHs has been reported to date.

An increasing number of environmental analytical laboratories are now equipped with GC/HRMS because of the need for $\mathrm{PCDD} / \mathrm{F}$ analysis where most legislation requires the application of GC/HRMS instrumentation such as laid down in EPA 1613 or 8290, EN-1948. For the Global Monitoring Plan under the Stockholm Convention, GC/HRMS is still considered the "golden standard" [33]. In this study, an isotopic dilution GC/HRMS method using five ${ }^{13} \mathrm{C}$-labelled chlorinated or brominated PAH congeners and one dlabelled brominated PAH congener as the internal standards was developed for the simultaneous accurate qualification and quantification of 38 congeners and their homologs of Cl-PAHs and Br-PAHs. The developed method could greatly improve the method selectivity and avoid possible interference from complex environmental matrices. The method developed in this study will be a powerful technique for analysis of a broad spectrum of environmental contaminants and evaluation of the health risk associated with $\mathrm{Cl}-\mathrm{PAHs}$ and Br-PAHs in the environment.

\section{Materials and methods}

\subsection{Chemicals}

Native Cl-PAH standards were obtained as follows: 2,7-dichlorofluorene (2,7- $\left.\mathrm{Cl}_{2} \mathrm{Fle}\right)$ from Toronto Research Chemicals (Toronto, Canada), 1-chloroanthracene (1ClAnt), 2-chloroanthracene (2-ClAnt), 1,4-dichloroanthracene (1,4-Cl $\left.{ }_{2} \mathrm{Ant}\right)$, 1,5-dichloroanthracene (1,5- $\left.\mathrm{Cl}_{2} \mathrm{Ant}\right)$ and 1,5,9,10tetrachloroanthracene $\left(1,5,9,10-\mathrm{Cl}_{4} \mathrm{Ant}\right)$ from Sigma-Aldrich (MO, USA), 9-chlorophenanthrene (9-ClPhe), 9-chloroanthracene (9-ClAnt), 1-chloropyrene (1-ClPyr), 7-chlorobenz[a]anthracene (7-ClBaA), and 7,12-dichlorobenz[a]anthracene (7,12- $\left.\mathrm{Cl}_{2} \mathrm{BaA}\right)$ from Cambridge Isotope Laboratories (MA, USA). 2-chlorophenanthrene (2-ClAnt), 9,10-dichloroanthracene $\left(9,10-\mathrm{Cl}_{2} \mathrm{Ant}\right)$ and 9chlorofluorene (9-ClFle) were brought from Matrix Scientific (MA, USA), and 3-chlorophenanthrene (3-ClPhe), 9,10dichlorophenanthrene $\left(9,10-\mathrm{Cl}_{2} \mathrm{Phe}\right)$, 3-chlorofluoranthene (3-ClFlu), 3,8-dichlorofluoranthene $\left(3,8-\mathrm{Cl}_{2} \mathrm{Flu}\right)$, and 6chlorobenzo[a]pyrene (6-ClBaP) were synthesized by Pharmaron (Beijing, China). Native Br-PAH standards were obtained as follows: 5-bromoacenaphthene (5-BrAna), 2-bromofluorene (2-BrFle), 1,2-dibromoacenaphthylene (1,2- $\left.\mathrm{Br}_{2} \mathrm{Any}\right)$, 3bromophenanthrene (3-BrPhe), 9-bromophenanthrene (9-BrPhe), 9-bromoanthracene (9-BrAnt), 2,7-dibromofluorene (2,7$\mathrm{Br}_{2}$ Fle), 9,10-dibromoanthracene (9,10- $\left.\mathrm{Br}_{2} \mathrm{Ant}\right)$, 4-bromopyrene (4-BrPyr), 9,10-dibromophenanthrene (9,10- $\left.\mathrm{Br}_{2} \mathrm{Phe}\right)$, and 1-bromopyrene (1-BrPyr) from Sigma-Aldrich (MO, USA), 2-bromophenanthrene (2-BrPhe), 1-bromoanthracene (1BrAnt), 3-bromofluoranthrene (3-BrFlu), 1,8-dibromoanthracene (1,8- $\left.\mathrm{Br}_{2} \mathrm{Ant}\right), \quad 1,5$-dibromoanthracene $\left(1,5-\mathrm{Br}_{2} \mathrm{Ant}\right)$, and $1,6-$ 
dibromopyrene (1,6- $\left.\mathrm{Br}_{2} \mathrm{Pyr}\right)$ from Tokyo Chemical Industry (Tokyo, Japan), 7-bromobenz[a]anthracene (7-BrBaA) from Cambridge Isotope Laboratories (MA, USA), and 2-bromotriphenylene (2-BrTriph) from Matrix Scientific (MA, USA). ${ }^{13}$ C-labelled 1-chloropyrene $\quad\left({ }^{13} \mathrm{C}_{6}-1-\mathrm{ClPyr}\right), \quad$ 7-chlorobenz[a]anthracene $\left({ }^{13} \mathrm{C}_{6}-7-\mathrm{ClBaA}\right), \quad$ 7-bromobenz[a]anthracene $\quad\left({ }^{13} \mathrm{C}_{6}-7-\mathrm{BrBaA}\right)$ and 7,12-dichlorobenz[a]anthracene $\left({ }^{13} \mathrm{C}_{6}-7,12-\mathrm{Cl}_{2} \mathrm{BaA}\right)$ were bought from Cambridge Isotope Laboratories (MA, USA), and 9-chlorophenanthrene ( ${ }^{13} \mathrm{C}_{6}$-9-ClPhe), 2-chloroanthracene $\left({ }^{13} \mathrm{C}_{6}\right.$ 2 -ClAnt), and $d$-labelled 9-bromophenanthracene ( $d_{9}-9$-BrPhe) were from Toronto Research Chemicals (Toronto, Canada). The organic solvents were all pesticide grade.

\subsection{Sample collection}

Six ambient air samples and six stack gas samples from waste incinerators were used to evaluate the established GC/HRMS method for congener-specific analysis of Cl-PAHs and Br-PAHs. Air samples were collected using two high-volume samplers (Echo Hivol, Tecora Co., Paris, France) on the rooftop of a building on the campus of the Research Center for Eco-Environmental Sciences, Chinese Academy of Sciences. Contaminants in the gas phase of air were adsorbed onto polyurethane foam (PUF; Tisch Environmental, Cleves, OH, USA), while particles in the air were trapped on cleaned quartz fiber filters (QFFs; Ahlstrom Munktell, Sweden). A breakthrough experiment was conducted before air sampling to measure the suitable sampling volume for the PUFs. A second PUF was put behind the first PUF to trap the penetrated organics in the air. The concentrations of the Cl-PAHs and Br-PAHs in the second PUF were lower than $5 \%$ of those in the first PUF under the sampling volume of this study, indicating satisfactory sampling recoveries.

Stack gas samples were collected from four waste incinerators using an automatic isokinetic sampling method, including two municipal solid waste incinerators (MSWI) (GA, SY), one medical waste incinerator (ST), and one hazardous waste incinerator (RT). About 50 g XAD-2 resin (20-60 mesh) packed in a quartz tube was used as adsorbent for collecting the stack gas samples. For each MSWI, two stack gas samples were collected. The method for sampling stack gas from industrial thermal sources has been validated and widely applied in stack gas sampling for POP analysis in our previous studies $[29,34,35]$.

\subsection{Extraction and pretreatment}

Ambient air samples and stack gas samples were spiked with $1 \mathrm{ng}$ of the six isotopic $\mathrm{Cl}-\mathrm{PAH}$ and $\mathrm{Br}-\mathrm{PAH}$ internal standards $\left({ }^{13} \mathrm{C}_{6}\right.$ 9-ClPhe, ${ }^{13} \mathrm{C}_{6}-2$-ClAnt, ${ }^{13} \mathrm{C}_{6}-1$-ClPyr, ${ }^{13} \mathrm{C}_{6}-7-\mathrm{ClBaA},{ }^{13} \mathrm{C}_{6}-7-\mathrm{BrBaA}$ and $d_{9}-9$-BrPhe). Soxhlet extraction and accelerate solvent extraction methods (such as ASE, Thermal Fisher) are both widely used and recognized method for extraction of semi-volatile organic pollutants. Air samples were extracted under high pressure (using an ASE, Thermo Fisher) at $120^{\circ} \mathrm{C}$ using a $1: 1(\mathrm{v} / \mathrm{v})$ mixture of hexane (Hex) and dichloromethane (DCM). Stack gas samples with $\mathrm{Cl}$-/Br-PAHs entrapped in XAD-2 resins were Soxhlet extracted with toluene for about $20 \mathrm{~h}$. The extracted samples were then concentrated by a rotary evaporator, and cleaned with a silica column, a convertible active carbon column and a GPC column. The extracts were reduced to about $50 \mu \mathrm{L}$ by rotary evaporation under nitrogen. ${ }^{13} \mathrm{C}_{6}-7,12-\mathrm{Cl}_{2} \mathrm{BaA}$ ( $1 \mathrm{ng}$ of mass) was spiked as the injection standard before instrumental analysis. Blanks have been done along with each batch of the samples.

\subsection{Instrumental analysis}

Congener-specific analysis of $\mathrm{Cl}-\mathrm{PAHs}$ and $\mathrm{Br}$-PAHs was performed by GC coupled to HRMS (DFS, Thermo Fisher).
Separation was achieved on a DB-5 MS capillary column $(60 \mathrm{~m} \times 0.25 \mathrm{~mm} \times 0.25 \mu \mathrm{m}$, Agilent Technologies). Splitless injection was used. The initial oven temperature was $50^{\circ} \mathrm{C}$, then increased to $175^{\circ} \mathrm{C}$ at $25^{\circ} \mathrm{Cmin}^{-1}$, then to $200^{\circ} \mathrm{C}$ at $5^{\circ} \mathrm{C} \mathrm{min}^{-1}$, where it was held for $28 \mathrm{~min}$, and then increased to $300^{\circ} \mathrm{C}$ at $8^{\circ} \mathrm{C} \mathrm{min}^{-1}$, where it was held for another $10 \mathrm{~min}$, then to $305^{\circ} \mathrm{C}$ at $0.5^{\circ} \mathrm{C} \mathrm{min}-1$, held for $5 \mathrm{~min}$. The injector, auxiliary and ion source were $280^{\circ} \mathrm{C}, 290^{\circ} \mathrm{C}$ and $250^{\circ} \mathrm{C}$, respectively. The electron energy of HRMS was set to $45 \mathrm{eV}$, tuned and operated at a resolution of above 10,000 and data were acquired under selected ion mode (SIM).

\section{Results and discussion}

\subsection{Optimization of the cleanup procedure}

Columns packed with sulfuric acid silica gel are commonly used to remove the potential interference caused by lipids, pigments or other impurities from complex environmental samples prior to analysis for many POPs in environmental samples, such as PCDD/Fs, PCBs and polychlorinated naphthalenes (PCNs) [36,37]. Some previous studies used sulfuric acid silica gel as a pretreatment material prior to analysis of organohalogens, including some $\mathrm{Cl}-\mathrm{PAH}$ and $\mathrm{Br}$ PAH congeners [38,39]. Thus, the applicability of sulfuric acid silica gel as the cleanup material for analysis of $\mathrm{Cl}$-PAHs and $\mathrm{Br}$-PAHs was evaluated in the present study. To accomplish this, sulfuric acid silica gels with different mass loads (11\%, $22 \%$ and $44 \%)$ were prepared and evaluated. Briefly, $4 \mathrm{~g}$ of sulfuric acid silica gel was packed into a column with an inner diameter of $1.5 \mathrm{~cm}$, after which the mixture solutions of $\mathrm{Cl}-\mathrm{PAHs}$ and $\mathrm{Br}$-PAHs were passed through the columns and then eluted with $150 \mathrm{~mL}$ of dichloromethane (DCM) and hexane (Hex) $(1: 4, v / v)$. However, several congeners of Cl-PAHs and $\mathrm{Br}$-PAHs with the parent compounds of Ant, Pyr, and BaA were completely destroyed after passing through the sulfuric acid silica gel column, even when the lowest mass load (11\%) of sulfuric acid silica gels was used (Fig. S1). Thus, the sulfuric acid silica gel column, which is widely used to remove potential interference from sample matrices before instrumental analysis for POPs, is not suitable for pretreatment prior to analysis of $\mathrm{Cl}-\mathrm{PAHs}$ and $\mathrm{Br}-\mathrm{PAHs}$ in environmental samples. This further increases the necessity of using HRMS to greatly improve the selectivity and sensitivity for congener-specific analysis of $\mathrm{Cl}-\mathrm{PAHs}$ and $\mathrm{Br}-\mathrm{PAHs}$ in environmental samples.

Finally, a column packed with $2 \mathrm{~g}$ active silica gel and topped with $2-3 \mathrm{~cm}$ anhydrous sodium sulfate was used for pretreatment of Cl-PAHs and Br-PAHs. The elution curves of Cl-PAH and $\mathrm{Br}-\mathrm{PAH}$ congeners for the active silica gel column are shown in Fig. S2. This column was pre-cleaned with $100 \mathrm{~mL}$ hexane, after which the $\mathrm{Cl}$ $\mathrm{PAH}$ and Br-PAH congeners in the column were eluted by a $60 \mathrm{~mL}$ mixture of Hex and $\operatorname{DCM}(4: 1, v / v)$. In addition to the active silica gel, a convertible active carbon column and GPC column could be used for further pretreatment. The elution curves and detailed information for the two columns and the elution solvents are shown in Figs. S3 and S4.

\subsection{Traces for qualification and quantification of $\mathrm{Cl}-\mathrm{PAH}$ and Br-PAH congeners}

A stock solution composed of $19 \mathrm{Cl}-\mathrm{PAH}$ and $19 \mathrm{Br}$-PAH native standards as well as seven labelled $\mathrm{Cl}-\mathrm{PAH}$ and $\mathrm{Br}-\mathrm{PAH}$ standards was prepared and used to optimize the GC/HRMS operating parameters for congener identification and quantification of $\mathrm{Cl}-\mathrm{PAH}$ and Br-PAHs. The satisfactory separations of 38 congeners could be achieved within $65 \mathrm{~min}$ as shown in Fig. 1 and Table 1. The 1-ClAnt and 2-ClAnt and the 9-BrPhe and 2-BrPhe could not be separated by the $30 \mathrm{~m}$ capillary DB- $5 \mathrm{MS}$ column; therefore, a $60 \mathrm{~m}$ capil- 


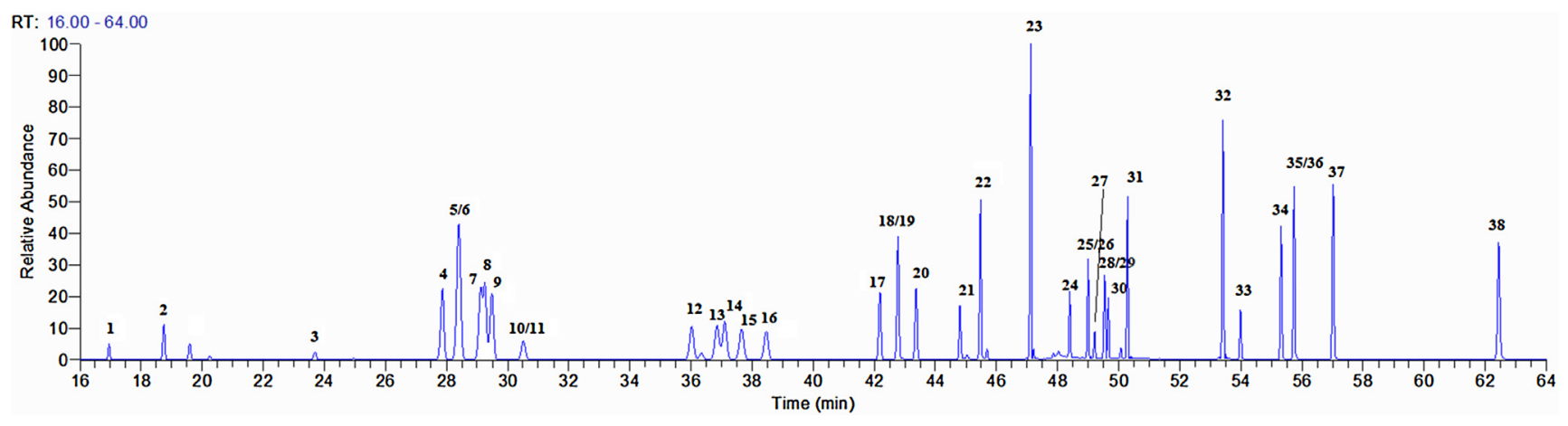

Fig. 1. Total ion chromatography of the Cl-PAHs and Br-PAHs.

Table 1

Retention times, quantification and qualification traces for $\mathrm{Cl}-\mathrm{PAH}$ and $\mathrm{Br}-\mathrm{PAH}$ congeners.

\begin{tabular}{|c|c|c|c|c|c|}
\hline Number & Compound & Retention time & Quantification traces & Qualification traces & Ratios \\
\hline \multicolumn{6}{|c|}{ Injection Standard: } \\
\hline \multicolumn{6}{|c|}{ The ${ }^{13} \mathrm{C}$-Labelled or the D-Labelled Compounds are Internal Standards } \\
\hline (1) & ${ }^{13} \mathrm{C}_{6}-9-\mathrm{ClPhe}$ & 28.37 & 218.0594 & 220.0564 & 0.32 \\
\hline 1 & 9-ClFle & 16.96 & 200.0393 & 202.0363 & 0.32 \\
\hline 2 & 5-BrAna & 19.59 & 233.9867 & 234.9901 & 0.13 \\
\hline 3 & 2-BrFle & 23.70 & 245.9967 & 246.9901 & 0.14 \\
\hline 4 & 3-ClPhe & 27.87 & 212.0393 & 214.0363 & 0.32 \\
\hline $5 / 6$ & 9-ClPhe/2-ClPhe & 28.41 & 212.0393 & 214.0363 & 0.32 \\
\hline (2) & ${ }^{13} \mathrm{C}_{6}-2-\mathrm{ClAnt}$ & 29.24 & 218.0594 & 220.0564 & 0.32 \\
\hline 7 & 1- ClAnt & 29.12 & 212.0393 & 214.0363 & 0.32 \\
\hline 8 & 2- ClAnt & 29.24 & 212.0393 & 214.0363 & 0.32 \\
\hline 9 & 9- ClAnt & 29.49 & 212.0393 & 214.0363 & 0.32 \\
\hline 10 & 2,7- $\mathrm{Cl}_{2}$ Fle & 30.50 & 234.0003 & 235.0037 & 0.14 \\
\hline 11 & 1,2- $\mathrm{Br}_{2}$ Any & 30.57 & 309.8816 & 307.8836 & 0.51 \\
\hline (3) & $\mathrm{D}_{9}-9$-BrPhe & 36.33 & 265.0452 & 267.0431 & 0.97 \\
\hline 12 & 3-BrPhe & 36.03 & 257.9867 & 255.9888 & 1.03 \\
\hline 13 & 9-BrPhe & 36.86 & 257.9867 & 255.9888 & 1.03 \\
\hline 14 & 2-BrPhe & 37.1 & 257.9867 & 255.9888 & 1.03 \\
\hline 155 & 1-BrAnt & 37.65 & 257.9867 & 255.9888 & 1.03 \\
\hline 16 & 9-BrAnt & 38.46 & 257.9867 & 255.9888 & 1.03 \\
\hline 17 & $1,4-\mathrm{Cl}_{2}$ Ant & 42.19 & 246.0003 & 247.0037 & 0.16 \\
\hline $18 / 19$ & $1,5-\mathrm{Cl}_{2}$ Ant $/ 9,10-\mathrm{Cl}_{2}$ Ant & 42.78 & 246.0003 & 247.0037 & 0.16 \\
\hline 20 & $9,10-\mathrm{Cl}_{2}$ Phe & 43.36 & 246.0003 & 247.0037 & 0.16 \\
\hline 21 & 2,7-Br 2 Fle & 44.81 & 323.8972 & 325.8952 & 0.49 \\
\hline 22 & 3-ClFlu & 45.48 & 236.0393 & 238.0363 & 0.32 \\
\hline (4) & ${ }^{13} \mathrm{C}_{6}-1-\mathrm{ClPyr}$ & 47.11 & 242.0594 & 244.0564 & 0.32 \\
\hline 23 & 1-ClPyr & 47.12 & 236.0393 & 238.0363 & 0.32 \\
\hline 24 & 3-BrFlu & 48.39 & 279.9888 & 282.9901 & 0.17 \\
\hline $25 / 26$ & 1,8- $\mathrm{Br}_{2} \mathrm{Ant} / 1,5-\mathrm{Br}_{2}$ Ant & 49.00 & 335.8972 & 337.8952 & 0.49 \\
\hline 27 & $9,10-\mathrm{Br}_{2}$ Ant & 49.22 & 335.8972 & 337.8952 & 0.49 \\
\hline 28 & 4-BrPyr & 49.54 & 279.9888 & 282.9901 & 0.17 \\
\hline 29 & $9,10-\mathrm{Br}_{2}$ Phe & 49.55 & 335.8972 & 337.8952 & 0.49 \\
\hline 30 & 1-BrPyr & 49.67 & 279.9888 & 282.9901 & 0.17 \\
\hline 31 & $3,8-\mathrm{Cl}_{2} \mathrm{Flu}$ & 50.29 & 270.0003 & 271.9974 & 0.64 \\
\hline (5) & ${ }^{13} \mathrm{C}_{6}-7-\mathrm{ClBaA}$ & 53.41 & 268.0750 & 270.0721 & 0.32 \\
\hline 32 & 7-ClBaA & 53.41 & 262.0549 & 264.0520 & 0.32 \\
\hline 33 & $1,5,9,10-\mathrm{Cl}_{4}$ Ant & 53.98 & 315.9194 & 317.9165 & 0.48 \\
\hline (6) & ${ }^{13} \mathrm{C}_{6}-7-\mathrm{BrBaA}$ & 55.74 & 312.0245 & 314.0225 & 0.97 \\
\hline 34 & 2-BrTriph & 55.31 & 306.0044 & 308.0024 & 0.97 \\
\hline 35 & 1,6- $\mathrm{Br}_{2} \mathrm{Pyr}$ & 55.73 & 359.8972 & 361.8952 & 0.49 \\
\hline 36 & 7-BrBaA & 55.73 & 306.0044 & 308.0024 & 0.97 \\
\hline 37 & $7,12-\mathrm{Cl}_{2} \mathrm{BaA}$ & 57.03 & 296.0160 & 298.0130 & 0.64 \\
\hline 38 & 6-ClBaP & 62.44 & 286.0549 & 288.0520 & 0.32 \\
\hline
\end{tabular}

lary DB-5 MS column was used and a better separation of many more congeners was achieved (Fig. S5). The resolutions $(R)$ of the 1-ClAnt/2-ClAnt and 9-BrPhe/2-BrPhe were calculated to be 0.93 and 1.14 , respectively.

The selection of monitored traces used for identification and quantification of each congener of Cl-PAHs and Br-PAHs is very important for improving the sensitivity and selectivity of the HRMS method. Electron ionization (EI) was used as the ionization mode for HRMS. The ionized molecules were ionized by the electron impact emitted by the filament, selected by the magnetic field, and focused by the electric field. Two traces with high abundance for each congener were selected for the congener identifications 

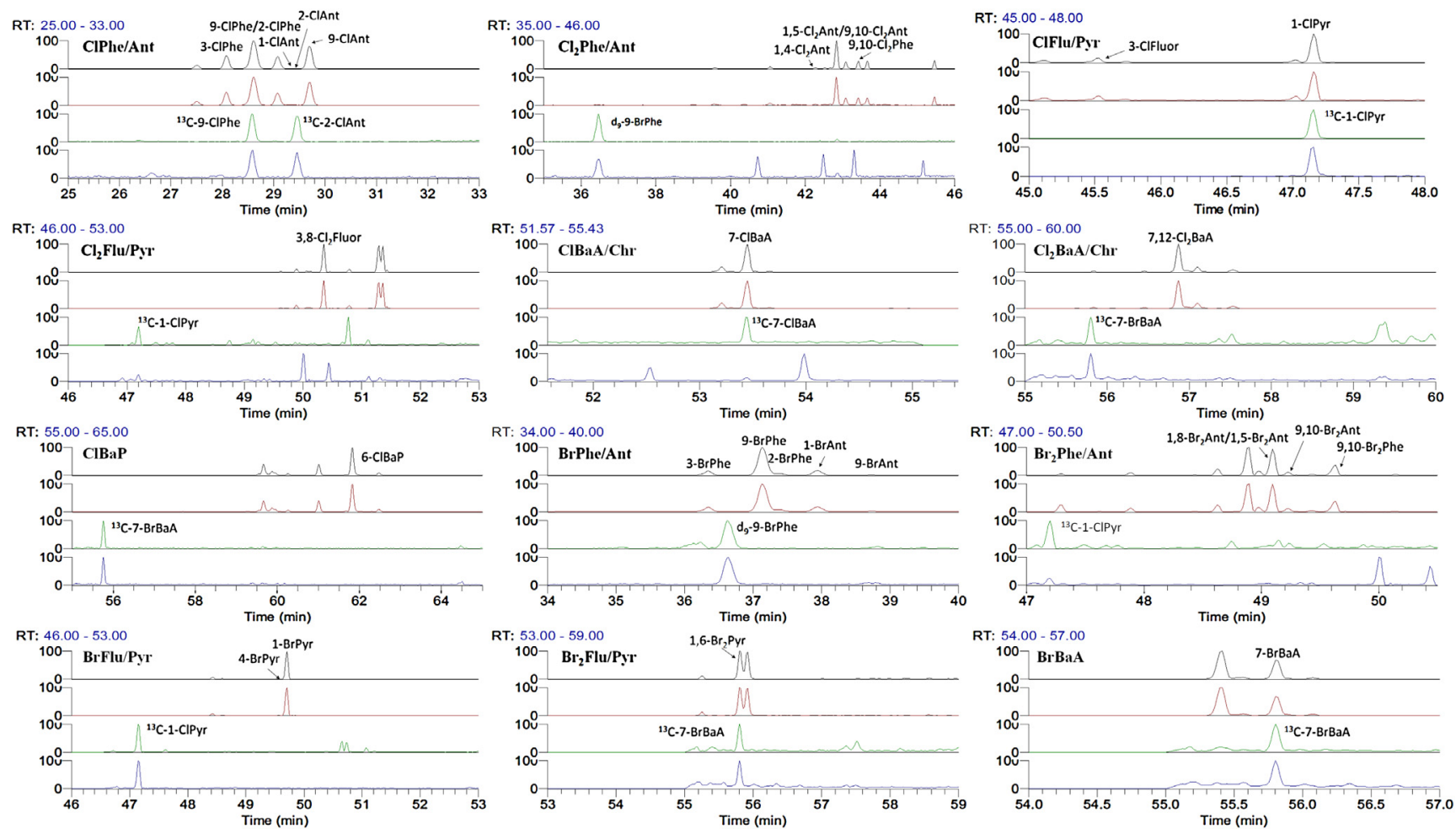

Fig. 2. Chromatograms of $\mathrm{Cl}-\mathrm{PAH}$ and $\mathrm{Br}-\mathrm{PAH}$ congeners and homologues, and their labelled internal standards.

and quantifications. Thus, the protonated molecule $\mathrm{M}^{\bullet+}$ and its halogenated isotopic protonated molecule $[\mathrm{M}+2]^{\bullet+}$ were normally selected as the quantification and qualification traces for the congeners of $\mathrm{Cl}-\mathrm{PAHs}$ and $\mathrm{Br}$-PAHs. Comparison of the ratios of the two monitored traces with the theoretical ratios of the halogens and their isotopes ( $3: 1$ for chlorine and $1: 1$ for bromine) was used to ensure the accuracy of congener identifications. For most of the $\mathrm{Cl}-\mathrm{PAH}$ and $\mathrm{Br}-\mathrm{PAH}$ congeners, monitoring of the protonated molecule $\mathrm{M}^{\bullet+}$ and its halogenated isotopic protonated molecule $[\mathrm{M}+2]^{\bullet+}$ could achieve satisfactory identification and quantification results. For a few congeners, including 4-BrPyr and 1-BrPyr, monitoring of the $m / z 281.9867(\mathrm{M}+2)$ as the qualification ion, which was the isotopic protonated molecule weight, would produce a low signal to noise ratio. Therefore, some other fragments with less abundance (as shown in Table 1) were selected as the monitoring ions for these congeners, which improved the sensitivity by nearly two times.

\subsection{Congener and homolog quantifications of $\mathrm{Cl}-\mathrm{PAHs}$ and Br-PAHs using 13C-labelled congeners as internal standards}

Currently, there is no available method of using ${ }^{13} \mathrm{C}$-labelled congeners as internal standards for determination of $\mathrm{Cl}$-PAHs and Br-PAHs in environmental samples. In this study, six labelled standards, ${ }^{13} \mathrm{C}_{6}-9$-ClPhe, ${ }^{13} \mathrm{C}_{6}-2$-ClAnt, ${ }^{13} \mathrm{C}_{6}-1$-ClPyr, ${ }^{13} \mathrm{C}_{6}-7$-ClBaA, ${ }^{13} \mathrm{C}_{6}-7-\mathrm{BrBaA}$ and $\mathrm{d}_{9}-9-\mathrm{Br}$ Phe, were used as internal standards for the accurate qualification and quantification of $19 \mathrm{Cl}-\mathrm{PAH}$ and $19 \mathrm{Br}$-PAH congeners. It is essential to establish the relationships between native congeners and their corresponding labelled internal standards for congener qualification and quantification. ${ }^{13} \mathrm{C}_{6}-7,12-\mathrm{Cl}_{2} \mathrm{BaA}$ was used as the injection standard for evaluation of the recoveries of ${ }^{13} \mathrm{C}$-labelled internal standards. The relationship between the ${ }^{13} \mathrm{C}$-labelled internal standards and the injection standard was also established and is shown in Table 1. Calculation of the relative response factors (RRF) for the congeners, and quan- tification method for the congeners were given in supplementary material. Recoveries of the internal standards could be calculated at the same time.

Because of the large numbers of congeners and the lack of available individual standards of $\mathrm{Cl}$-PAHs and $\mathrm{Br}-\mathrm{PAHs}$, it is not feasible to achieve congener-specific qualifications and quantifications for all of the congeners of $\mathrm{Cl}$-PAHs and $\mathrm{Br}$-PAHs in environmental samples. Qualification and quantitation of homolog concentrations and distributions could provide important information for the environmental characteristics. The monitored traces for the homologs were set to be the same as known congeners (standard chemicals that were synthesized or commercially available) in the same homolog (Table S1). Chromatograms of the two monitored traces of $\mathrm{Cl}-\mathrm{PAH}$ and $\mathrm{Br}-\mathrm{PAH}$ congeners and homologs and their internal standards in the samples are shown in Fig. 2. As shown in Fig. 2, more congeners than the known congeners were detected in the samples. Moreover, some of these additional congeners had high peak areas, which suggested high potential concentrations. Quantification of the homologs could take these congeners into consideration.

Eq. (1) was used for quantification of the homologs based on the average RRF of the known congeners relative to their corresponding labelled internal standards. $C_{u}$ was the concentration of the homologs in the samples. $A 1_{u}$ and $A 2_{u}$ are the peak areas of primary and secondary traces of the homologs in the samples, $C_{i e}$ is the concentration of the corresponding internal standard, and $A 1_{i e}$ and $A 2_{i e}$ are the peak areas of the primary and secondary traces for the labelled internal standards in the samples. The concentrations of homologs were the sum of the congener concentrations. This method could quantify the concentrations of homologs, including congeners that their chemical standards are available and unavailable.

$C_{u}=\frac{\left(A 1_{u}+A 2_{u}\right) C_{i e}}{\left(A 1_{i e}+A 2_{i e}\right) R R F}$ 
3.4. Validation of the established isotopic dilution GC/HRMS method

The RRFs from triple injections of $\mathrm{Cl}-\mathrm{PAH}$ and $\mathrm{Br}-\mathrm{PAH}$ mixtures

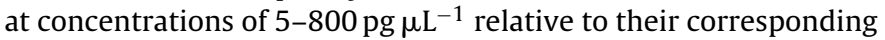
labelled internal standard are shown in Tables 2 and S2. The relative standard deviations (RSDs) of RRFs for 38 congeners in triple analysis were below $15 \%$ over the eight point calibration range, indicating robust RRFs. Calibration curves were obtained by plotting the area response of primary and secondary masses of target congeners relative to that of the corresponding internal standard (as the vertical axis) against the ratios of concentrations of target compounds to that of the corresponding internal standard (as the horizontal axis). Significant linear correlations were obtained (linear correlation coefficients, $R^{2}>0.977$ ) for the $38 \mathrm{Cl}-\mathrm{PAH}$ and Br-PAH congeners.

Standard solution of CS1 with concentrations as low as $5 \mathrm{ng} \mathrm{mL}^{-1}$ for each congener was analyzed by the GC/HRMS method, and the signal to noise $(\mathrm{S} / \mathrm{N})$ ratios for the quantification traces of 38 congeners were all greater than 10 . The measurements were repeated seven times, and three times the standard deviation was calculated to be the instrumental detection limit (IDL) as previously described $[40,41]$. As shown in Table S3, the IDL were calculated to be $0.2 \mathrm{pg}-1.8 \mathrm{pg}$ for $\mathrm{Cl}-\mathrm{PAH}$ congeners and $0.7 \mathrm{pg}-2.7 \mathrm{pg}$ for the Br-PAH congeners. In addition to the instrumental detection limits, the method detection limits (MDL) were also evaluated. To accomplish this, congener solutions at concentrations 10-times those of the detection limits were spiked into five blank air samples (a PUF and a filter for absorbing air contaminants) and five blank XAD samples (XAD-2 resin: used for capturing contaminants in stack gas from waste incinerators). The extraction, pretreatment and analysis of the spiked blank samples were conducted using the same procedure as for sample pretreatment. The MDL was considered to be three times the standard deviation. The MDLs ranged from $0.5 \mathrm{fg} \mathrm{m}^{-3}$ to $5.6 \mathrm{fg} \mathrm{m}^{-3}$ for Cl-PAH congeners and $0.7 \mathrm{fg} \mathrm{m}^{-3}$ to $4.8 \mathrm{fg} \mathrm{m}^{-3}$ for Br-PAH congeners for air samples on air volumes of $500 \mathrm{~m}^{3}$. This MDLs for air samples were about two orders of magnitude lower than previous studies using GCHRMS method with $d$-labelled PAH standards as internal standards, of which the MDLs were $0.03 \mathrm{pg} \mathrm{m}^{-3}$ to $1.41 \mathrm{pg} \mathrm{m}^{-3}$ for Cl-PAHs on air volumes of $700 \mathrm{~m}^{3}$, and $0.014 \mathrm{pg} \mathrm{m}^{-3}$ to $0.6 \mathrm{pg} \mathrm{m}^{-3}$ for Br-PAHs on air volumes of $4000 \mathrm{~m}^{3}$ [2,42]. The evaluated MDLs ranged from $0.7 \mathrm{pg} \mathrm{m}^{-3}$ to $3.8 \mathrm{pg} \mathrm{m}^{-3}$ for $\mathrm{Cl}$-PAH congeners and $0.5 \mathrm{pg} \mathrm{m}^{-3}$ to $4.3 \mathrm{pg} \mathrm{m}^{-3}$ for Br-PAH congeners in stack gas samples of $2 \mathrm{~m}^{3}$.

The recoveries of the native $\mathrm{Cl}-\mathrm{PAH}$ and $\mathrm{Br}-\mathrm{PAH}$ congeners during the pretreatment procedures were also evaluated. Standard solutions with $1 \mathrm{ng}$ of each congener of $\mathrm{Cl}$-PAHs and $\mathrm{Br}$-PAHs were spiked into five blank air samples and five blank XRD samples. The sample extraction, pretreatment and instrumental analysis were then conducted following the established GC/HRMS method. As shown in Fig. S6, the average recoveries of the native Cl-PAH and $\mathrm{Br}$ PAH congeners ranged from $71.7 \%$ to $110.0 \%$ for Cl-PAH congeners, and from $65.7 \%$ to $99.7 \%$ for Br-PAH congeners. Recoveries of the labelled internal standards for Cl-PAHs and $\mathrm{Br}$-PAHs ranged from 77.1 to $105.9 \%$, which satisfied the requirements for trace analysis of POPs by the isotopic dilution GC/HRMS technique.

\subsection{Comparison of GC/HRMS with the GC/quadrupole MS method for congener-specific analysis of $\mathrm{Cl}-\mathrm{PAHs}$ and $\mathrm{Br}-\mathrm{PAHS}$}

Calibration curves for quantification of $\mathrm{Cl}-\mathrm{PAH}$ and $\mathrm{Br}-\mathrm{PAH}$ congeners by GC/quadrupole MS were also established with the goal of comparison with that of GC/HRMS. The same GC operating parameters were set for the GC/quadrupole MS as those of GC/HRMS. The obtained signal to noise ratios of the congener solution at concentrations of CS1 ( $\left.5 \mathrm{ng} \mathrm{mL}^{-1}\right)$ and CS2 (10 $\left.\mathrm{ng} \mathrm{mL}^{-1}\right)$ could not meet the requirements of congener-specific quantification and qualification based on the GC/quadrupole MS methods that are currently widely used. The detection limit for Cl-PAH congeners by GC/quadrupole MS was $0.34 \mathrm{ng}-1.9 \mathrm{ng}[9,43]$, which was obviously higher than that of $\mathrm{Cl}-\mathrm{PAH}$ congeners $(0.2 \mathrm{pg}-1.8 \mathrm{pg})$, and Br-PAH congeners $(0.7 \mathrm{pg}-2.7 \mathrm{pg})$ of the established GC/HRMS in this study. A sample with high concentrations of Cl-PAHs and Br-PAHs was also analyzed by the GC/HRMS and GC/quadrupole MS methods with the goal of further comparison, and the chromatograms generated by GC/HRMS and GC/quadrupole MS are shown in Fig. 3. The results revealed that the intensity of the congener peaks was obviously higher in the chromatogram generated by GC/HRMS than that generated by GC/quadrupole MS. Moreover, the chromatogram produced by GC/HRMS was obviously clearer than the GC/quadrupole MS chromatogram, indicating much better selectivity of GC/HRMS than GC/quadrupole MS. The higher selectivity of GC/HRMS than GC/quadrupole MS is very important to avoiding the potential interference caused by impurities and overestimation of the concentrations of Cl-PAHs and Br-PAHs in complex environmental samples, which could ensure the accuracy of congener-specific quantification.

\subsection{Application of established isotopic dilution GC/HRMS method to analysis of $\mathrm{Cl}-\mathrm{PAHs}$ and $\mathrm{Br}-\mathrm{PAHs}$ in atmospheric and stack gas samples}

The established GC/HRMS method was applied to congenerspecific analysis of $\mathrm{Cl}$-PAHs and $\mathrm{Br}-\mathrm{PAHs}$ in six stack gas samples collected from waste incinerators and six atmospheric samples. One blank sample was included for each batch of sample analysis. The congener concentrations of $\mathrm{Cl}$-PAHs and $\mathrm{Br}$-PAHs in the blanks were lower than $6 \%$ of those in the stack gas and atmosphere samples (Table S4). The recoveries of the labelled internal standards for $\mathrm{Cl}-\mathrm{PAHs}$ and $\mathrm{Br}-\mathrm{PAHs}$ in the stack gas and air samples ranged from $53 \%$ to $110 \%$ (38\% for ${ }^{13} \mathrm{C}_{6}-7-\mathrm{BrBaA}$ in one stack gas sample), which satisfied the requirements for trace analysis of POPs by the isotopic dilution GC/HRMS technique.

The congener concentrations of Cl-PAHs and Br-PAHs for stack gas samples are summarized in Table S5. The concentrations of $\sum{ }_{19} \mathrm{Cl}$-PAHs ranged from $6.22 \mathrm{ng} \mathrm{m}^{-3}$ to $156 \mathrm{ng} \mathrm{m}^{-3}$, while those of $\sum_{19} \mathrm{Br}$-PAHs ranged from $1.09 \mathrm{ng} \mathrm{m}^{-3}$ to $73.9 \mathrm{ng} \mathrm{m}^{-3}$ in the stack gas samples from waste incinerators. The dominant $\mathrm{Cl}-\mathrm{PAH}$ congener was 1-ClPyr, and its concentrations ranged from $1.88 \mathrm{ng} \mathrm{m}^{-3}$ to $75.7 \mathrm{ng} \mathrm{m}^{-3}$. The dominant Br-PAH congener was $1-\mathrm{BrPyr}$, and its concentrations ranged from $0.58 \mathrm{ng} \mathrm{m}^{-3}$ to $59.4 \mathrm{ng} \mathrm{m}^{-3}$. Major $\mathrm{Cl}-\mathrm{PAH}$ congeners in the stack gas samples also included 9-ClPhe/2ClPhe and 6-ClBaP, while 2-BrFle, 1,6- $\mathrm{Br}_{2} \mathrm{Pyr}$, 3-BrFlu and 7-BrBaA were major $\mathrm{Br}-\mathrm{PAH}$ congeners in these samples (Fig. 4). Previous studies have reported the concentrations of Cl-PAHs and Br-PAHs in fly ash samples from waste incinerators [44]. The congener distributions of Cl-PAHs and Br-PAHs in stack gas emissions found in this study was similar to that reported in a previous study, in which 1$\mathrm{ClPyr}$ and 7-ClBaA were identified as major $\mathrm{Cl}-\mathrm{PAH}$ congeners, and that 1-BrPyr and 7-BrBaA were the major Br-PAH congeners in fly ash from waste incinerators [44]. However, the dominant occurrence of other congeners including 2-ClPhe, 3-ClPhe, 7,12- $\mathrm{Cl}_{2} \mathrm{BaA}$, $1,6-\mathrm{Br}_{2}$ Pyr and 3-BrFlu in stack gas in this study has not previously been reported for fly ash samples [44]. The homolog concentrations of $\mathrm{Cl}-\mathrm{PAH}$ and $\mathrm{Br}$-PAHs in stack gases from waste incinerators were first analyzed and reported using the established isotopic dilution GC/HRMS method, and their concentrations are listed in Table S5. ClBaP was the major chlorinated homolog (average concentration, $49.4 \mathrm{ng} \mathrm{m}^{-3}$ ), followed by ClFlu/Pyr and ClPhe/Ant. The concentrations of dichlorinated homologs were lower than those of the corresponding monochlorinated homologs. For example, the concentrations of $\mathrm{Cl}_{2}$ Phe/Ant were lower than those of 
Table 2

Calibration curves, RRFs and correlation coefficients for $\mathrm{Cl}-\mathrm{PAH}$ and $\mathrm{Br}-\mathrm{PAH}$ congeners.

\begin{tabular}{|c|c|c|c|c|c|c|c|c|c|}
\hline Entry Identifier & $\mathrm{CS} 1-\mathrm{CS} 8\left(\mathrm{ng} \mathrm{mL}^{-1}\right)$ & Averaged RRF & $\mathrm{R}^{2}$ & RSD (\%) & Entry Identifier & $\mathrm{CS} 1-\mathrm{CS} 8\left(\mathrm{ng} \mathrm{mL}^{-1}\right)$ & Averaged RRF & $\mathrm{R}^{2}$ & RSD (\%) \\
\hline Cl-PAHs & & & & & Br-PAHs & & & & \\
\hline 9-ClFle & $5-800$ & 0.15 & 0.992 & 15 & 5-BrAna & $5-800$ & 0.28 & 0.995 & 7.1 \\
\hline 3-ClPhe & $5-800$ & 1.09 & 0.999 & 2.0 & 2-BrFle & $5-800$ & 0.18 & 0.996 & 9.5 \\
\hline 9-ClPhe/2-ClPhe & $10-1600$ & 2.40 & 0.999 & 11 & $1,2-\mathrm{Br}_{2}$ Any & $5-800$ & 0.21 & 0.968 & 8.2 \\
\hline 1-ClAnt & $5-800$ & 1.21 & 0.994 & 7.1 & 3-BrPhe & $5-800$ & 1.05 & 0.999 & 4.8 \\
\hline 2-ClAnt & $5-800$ & 0.83 & 0.994 & 6.8 & 9-BrPhe & $5-800$ & 1.11 & 0.998 & 4.8 \\
\hline 9-ClAnt & $5-800$ & 1.06 & 0.995 & 5.0 & 2-BrPhe & $5-800$ & 1.09 & 0.998 & 7.2 \\
\hline 2,7- $\mathrm{Cl}_{2} \mathrm{Fle}$ & $5-800$ & 0.24 & 0.999 & 7.1 & 1-BrAnt & $5-800$ & 0.91 & 0.997 & 7.0 \\
\hline $1,4-\mathrm{Cl}_{2}$ Ant & $5-800$ & 1.89 & 0.992 & 8.0 & 9-BrAnt & $5-800$ & 0.83 & 0.996 & 5.9 \\
\hline $1,5-\mathrm{Cl}_{2}$ Ant $/ 9,10-\mathrm{Cl}_{2}$ Ant & $10-1600$ & 2.95 & 0.991 & 8.0 & 2,7-Br ${ }_{2} \mathrm{Fle}$ & $5-800$ & 0.40 & 0.995 & 15 \\
\hline $9,10-\mathrm{Cl}_{2}$ Phe & $5-800$ & 1.68 & 0.988 & 10 & 3-BrFlu & $5-800$ & 0.49 & 0.992 & 5.4 \\
\hline 3-ClFlu & $5-800$ & 1.76 & 0.985 & 8.1 & $1,8-\mathrm{Br}_{2} \mathrm{Ant} / 1,5-\mathrm{Br}_{2}$ Ant & $10-1600$ & 0.60 & 0.984 & 8.3 \\
\hline 1-ClPyr & $5-800$ & 1.05 & 0.999 & 1.6 & $9,10-\mathrm{Br}_{2}$ Ant & $5-800$ & 0.32 & 0.980 & 5.6 \\
\hline $3,8-\mathrm{Cl}_{2}$ Flu & $5-800$ & 0.71 & 0.996 & 4.0 & 4-BrPyr & $5-800$ & 0.43 & 0.995 & 4.3 \\
\hline 7-ClBaA & $5-800$ & 1.03 & 0.999 & 2.8 & $9,10-\mathrm{Br}_{2}$ Phe & $5-800$ & 0.27 & 0.977 & 7.0 \\
\hline $1,5,9,10-\mathrm{Cl}_{4}$ Ant & $5-800$ & 0.32 & 0.997 & 4.2 & 1-BrPyr & $5-800$ & 0.46 & 0.996 & 7.8 \\
\hline 7,12-ClBaA & $5-800$ & 1.64 & 0.999 & 5.4 & 2-BrTriph & $5-800$ & 1.26 & 0.998 & 6.9 \\
\hline \multirow[t]{2}{*}{ 6-ClBaP } & $5-800$ & 1.66 & 0.997 & 7.3 & 1,6-BrPyr & $5-800$ & 0.85 & 0.995 & 4.4 \\
\hline & & & & & 7-BrBaA & $5-800$ & 1.07 & 0.999 & 7.2 \\
\hline
\end{tabular}
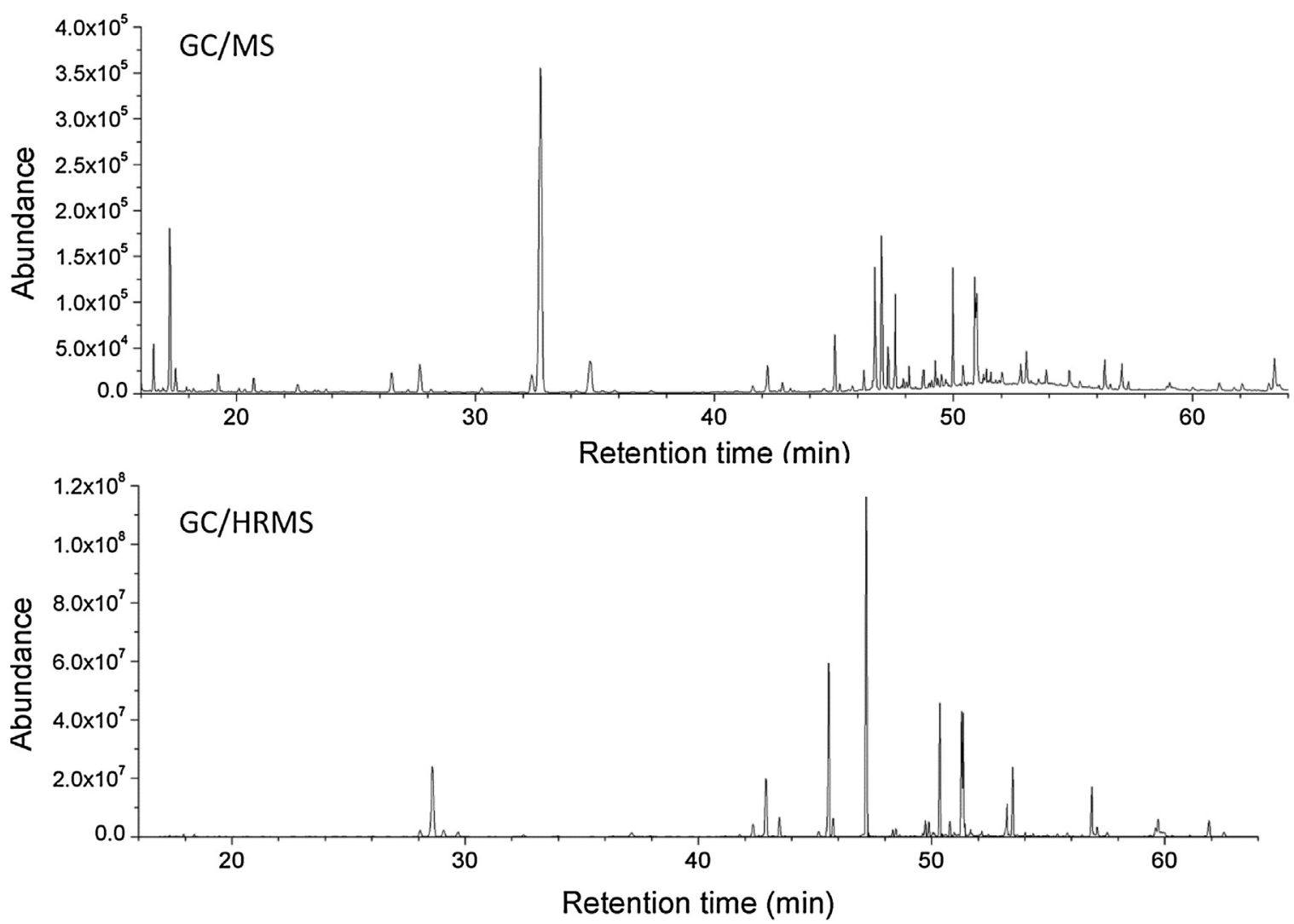

Fig. 3. Chromatograms for a sample in GC/HRMS and GC/MS.

ClPhe/Ant (Fig. 4). Among the brominated homologs, BrFlu/Pyr was the major homolog (average concentration, $19.1 \mathrm{ng} \mathrm{m}^{-3}$ ). The concentrations of dibrominated homologs were also lower than those of the corresponding monobrominated homologs. Homolog distributions varied widely among stack gas samples. For example, ClPyr/Flu showed higher fractions than ClBaP in RT and SY-2 samples, but lower fractions of $\mathrm{ClPyr} / \mathrm{Flu}$ than $\mathrm{ClBaP}$ were found in other stack gas samples. BrBaA/Chr showed higher fractions than BrPhe/Ant in GA-1, GA-2 and RT, but lower fractions of BrBaA/Chr than BrPhe/Ant were detected in ST, SY and SY-1. These patterns might provide helpful information for identifying the sources of $\mathrm{Cl}-\mathrm{PAHs}$ and $\mathrm{Br}-\mathrm{PAHs}$ in the environment.
For atmospheric samples, concentrations of $\sum{ }_{19} \mathrm{Cl}-\mathrm{PAHs}$ ranged from $98.5 \mathrm{pg} \mathrm{m}^{-3}$ to $422 \mathrm{pg} \mathrm{m}^{-3}$, while concentrations of $\sum_{19} \mathrm{Br}-\mathrm{PAHs}$ ranged from $3.34 \mathrm{pg} \mathrm{m}^{-3}$ to $51.9 \mathrm{pg} \mathrm{m}^{-3}$. 9-ClPhe/2-ClPhe was the dominant Cl-PAH congener (46.9 $\mathrm{pg} \mathrm{m}^{-3}-81.2 \mathrm{pg} \mathrm{m}^{-3}$ ), followed by 1-ClPyr, 3-ClFlu and 3-ClPhe (Fig. 4). The concentrations of $\sum{ }_{19} \mathrm{Cl}-\mathrm{PAHs}$ were in similar range with previous studies about the Cl-PAHs in air of Japan (18 $\mathrm{pg} \mathrm{m}^{-3}-330 \mathrm{pg} \mathrm{m}^{-3}$ ) [8]. With regard to Br-PAHs, study about the concentrations in both gaseous phase and particulate phase simultaneously was still unavailable. The concentrations of 11 BrPAH congeners in particulate matter in urban air in Japan were reported to be $0.08 \mathrm{pg} \mathrm{m}^{-3}-169 \mathrm{pg} \mathrm{m}^{-3}$ [2], which 

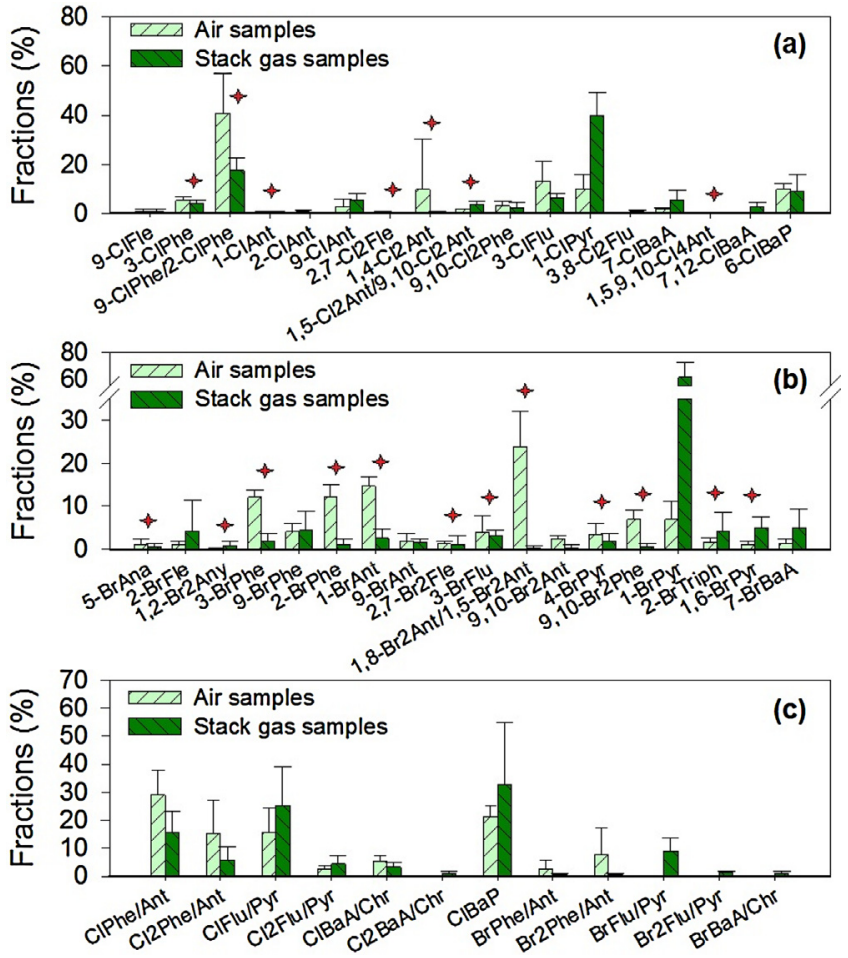

Fig. 4. Congener and homologue distributions of $\mathrm{Cl}-\mathrm{PAHs}$ and $\mathrm{Br}-\mathrm{PAHs}$ in atmospheric and stack gas samples. (a) Congener distributions of Cl-PAHs; (b) congener distributions of Br-PAHs; (c) homolog distributions of $\mathrm{Cl}-\mathrm{PAHs}$ and $\mathrm{Br}-\mathrm{PAHs} ;{ }^{*} \mathrm{Cl}-$ $\mathrm{PAH}$ and $\mathrm{Br}-\mathrm{PAH}$ congeners that were first reported for stack gas samples from waste incinerators and atmospheric samples.

was higher than that in this study $\left(1.45 \mathrm{pg} \mathrm{m}^{-3}-10.0 \mathrm{pg} \mathrm{m}^{-3}\right)$. $1,8-\mathrm{Br}_{2} \mathrm{Ant} / 1,5-\mathrm{Br}_{2} \mathrm{Ant}$ was the dominant $\mathrm{Br}-\mathrm{PAH}$ congener $\left(0.74 \mathrm{pg} \mathrm{m}^{-3}-20.0 \mathrm{pg} \mathrm{m}^{-3}\right)$, followed by 1-BrAnt, 3-BrPhe and 2-BrPhe. Among the Cl-PAH homologs, ClPhe/Ant was the major homolog (average concentration: $90.3 \mathrm{pg} \mathrm{m}^{-3}$ ), followed by $\mathrm{Cl}_{2}$ Phe/Ant and ClBaP. For Br-PAH homologs, the concentrations of $\mathrm{Br}_{2} \mathrm{Phe} /$ Ant (average concentration: $35.0 \mathrm{pg} \mathrm{m}^{-3}$ ) were higher than those of BrPhe/Ant (average concentration: $7.95 \mathrm{pg} \mathrm{m}^{-3}$ ). The concentrations of 3-ClPhe, 1-ClAnt, 2,7- $\mathrm{Cl}_{2}$ Fle, 1,4- $\mathrm{Cl}_{2}$ Ant, $1,5-$ $\mathrm{Cl}_{2}$ Ant and 1,5,9,10-Cl 4 Ant in the air samples were first reported for the $\mathrm{Cl}-\mathrm{PAH}$ congeners. This is also the first study to ever report the detection and concentrations of $13 \mathrm{Br}-\mathrm{PAH}$ congeners in air samples (Fig. 4).

\section{Conclusions}

An isotopic dilution GC/HRMS method using ${ }^{13} \mathrm{C}$-labelled and d-labelled congeners as internal standards for congener-specific analysis of chlorinated and brominated polycyclic aromatic hydrocarbons (Cl-PAHs and Br-PAHs) was established in this study. The detection limits of the GC/HRMS method were about three orders of magnitude lower than those of the GC/quadrupole MS, which is still widely used. The developed method was also the first to enable determination of $\mathrm{Cl}-\mathrm{PAH}$ and $\mathrm{Br}-\mathrm{PAH}$ homologs comprising congeners with the same molecular skeleton and the same number of substituted chlorines or bromines. Overall, many Cl-PAH and $\mathrm{Br}$-PAH congeners that were abundant in the atmosphere and stack gases released from waste incinerators were detected and reported for the first time using the established isotopic dilution GC/HRMS method, indicating that this method will be useful to studying environmental behavior and health risks associated with Cl-PAHs and Br-PAHs as new POPs.

\section{Acknowledgments}

This work was supported by the Chinese National 973 Program (2015CB453100), National Natural Science Foundation of China $(91543108,21477147)$, the Joint foundations from National Natural Science Foundation of China and United Nations Environment Programme (21361140359), the Strategic Priority Research Program of the Chinese Academy of Sciences (XDB14020102) and the Youth Innovation Promotion Association of the Chinese Academy of Sciences (2016038). We thank Dr. Thanh Wang for providing several $\mathrm{Cl}-/ \mathrm{Br}-\mathrm{PAH}$ standards for us.

\section{Appendix A. Supplementary data}

Supplementary data associated with this article can be found, in the online version, at doi: 10.1016/j.chroma.2017.06.022.

\section{References}

[1] T. Ohura, M. Morita, M. Makino, T. Amagai, K. Shimoi, Aryl hydrocarbon receptor-mediated effects of chlorinated polycyclic aromatic hydrocarbons, Chem. Res. Toxicol. 20 (2007) 1237-1241.

[2] T. Ohura, K.I. Sawada, T. Amagai, M. Shinomiya, Discovery of novel halogenated polycyclic aromatic hydrocarbons in urban particulate matters: occurrence, photostability, and AhR activity, Environ. Sci. Technol. 43 (2009) 2269-2275.

[3] Y. Horii, J.S. Khim, E.B. Higley, J.P. Giesy, T. Ohura, K. Kannan, Relative potencies of individual chlorinated and brominated polycyclic aromatic hydrocarbons for induction of aryl hydrocarbon receptor-mediated responses, Environ. Sci. Technol. 43 (2009) 2159-2165.

[4] J.L. Sun, H. Zeng, H.G. Ni, Halogenated polycyclic aromatic hydrocarbons in the environment, Chemosphere 90 (2013) 1751-1759.

[5] J. Ma, Y. Horii, J.P. Cheng, W.H. Wang, Q. Wu, T. Ohura, K. Kannan, Chlorinated and parent polycyclic aromatic hydrocarbons in environmental samples from an electronic waste recycling facility and a chemical industrial complex in China, Environ. Sci. Technol. 43 (2009) 643-649.

[6] B.X. Mai, H.M. Fu, G.Y. Sheng, Y.H. Kang, Z. Lin, G. Zhang, Y.S. Min, E.Y. Zeng, Chlorinated and polycyclic aromatic hydrocarbons in riverine and estuarine sediments from Pearl River Delta, China, Environ. Pollut. 117 (2002) 457-474.

[7] T. Ohura, Environmental behavior, sources, and effects of chlorinated polycyclic aromatic hydrocarbons, Sci. World J. 7 (2007) 372-380.

[8] T. Ohura, S. Fujima, T. Amagai, M. Shinomiya, Chlorinated polycyclic aromatic hydrocarbons in the atmosphere: seasonal levels, gas-particle partitioning, and origin, Environ. Sci. Technol. 42 (2008) 3296-3302.

[9] T. Ohura, A. Kitazawa, T. Amagai, M. Makino, Occurrence, profiles, and photostabilities of chlorinated polycyclic aromatic hydrocarbons associated with particulates in urban air, Environ. Sci. Technol. 39 (2005) 85-91.

[10] P. Haglund, T. Alsberg, A. Bergman, B. Jansson, Analysis of halogenated polycyclic aromatic-hydrocarbons in urban air, snow and automobile exhaust, Chemosphere 16 (1987) 2441-2450.

[11] S. Fujima, T. Ohura, T. Amagai, Simultaneous determination of gaseous and particulate chlorinated polycyclic aromatic hydrocarbons in emissions from the scorching of polyvinylidene chloride film, Chemosphere 65 (2006) 1983-1989.

[12] X.L. Wang, H.Y. Kang, J.F. Wu, Determination of chlorinated polycyclic aromatic hydrocarbons in water by solid-phase extraction coupled with gas chromatography and mass spectrometry, J. Sep. Sci. 39 (2016) 1742-1748.

[13] X.L. Wang, J.F. Wu, B. Liu, Pressurized liquid extraction of chlorinated polycyclic aromatic hydrocarbons from soil samples using aqueous solutions, RSC Adv. 6 (2016) 80017-80023.

[14] D. Wang, M. Piao, S. Chu, X. Xu, Chlorinated polycyclic aromatic hydrocarbons from polyvinylchloride combustion, Bull. Environ. Contam. Toxicol. 66 (2001) 326-333.

[15] D.L. Wang, X.B. Xu, S.G. Chu, D. Zhang Analysis and structure prediction of chlorinated polycyclic aromatic hydrocarbons released from combustion of polyvinylchloride, Chemosphere 53 (2003) 495-503.

[16] T. Ohura, Y. Kamiya, F. Ikemori, Local and seasonal variations in concentrations of chlorinated polycyclic aromatic hydrocarbons associated with particles in a Japanese megacity, J. Hazard. Mater. 312 (2016) 254-261.

[17] Y. Kamiya, F. Ikemori, T. Ohura, Optimisation of pre-treatment and ionisation for GC/MS analysis for the determination of chlorinated PAHs in atmospheric particulate samples, Int. J. Environ. Anal. Chem. 95 (2015) 1157-1168.

[18] T. Ieda, N. Ochiai, T. Miyawaki, T. Ohura, Y. Horii, Environmental analysis of chlorinated and brominated polycyclic aromatic hydrocarbons by comprehensive two-dimensional gas chromatography coupled to high-resolution time-of-flight mass spectrometry, J. Chromatogr. A 1218 (2011) 3224-3232

[19] C. Manzano, E. Hoh, S.L.M. Simonich, Improved separation of complex polycyclic aromatic hydrocarbon mixtures using novel column combinations in GCxGC/ToF-MS, Environ. Sci. Technol. 46 (2012) 7677-7684. 
[20] B. Wyrzykowska, D. Tabor, B.K. Gullett, Same-sample determination of ultratrace levels of polybromodiphenylethers polybromodibenzo-p-dioxins/Furans, and polychlorodibenzo-p-dioxins/Furans from combustion flue gas, Anal. Chem. 81 (2009) 4334-4342.

[21] B. van Bavel, D.W. Geng, L. Cherta, J. Nacher-Mestre, T. Portoles, M. Abalos, J. Saulo, E. Abad, J. Dunstan, R. Jones, A. Kotz, H. Winterhalter, R. Malisch, W. Traag, J. Hagberg, I.E. Jogsten, J. Beltran, F. Hernandez, Atmospheric-pressure chemical ionization tandem mass spectrometry (APGC/MS/MS) an alternative to high-resolution mass spectrometry (HRGC/HRMS) for the determination of dioxins, Anal. Chem. 87 (2015) 9047-9053.

[22] B. van Bavel, E. Abad, Long-term worldwide QA/QC of dioxins and dioxin-like PCBs in environmental samples, Anal. Chem. 80 (2008) 3956-3964.

[23] E. Holt, R. Von Der Recke, W. Vetter, D. Hawker, V. Alberts, B. Kuch, R. Weber, C. Gaus, Assessing dioxin precursors in pesticide formulations and environmental samples as a source of octachlorodibenzo-p-dioxin in soil and sediment, Environ. Sci. Technol. 42 (2008) 1472-1478.

[24] United States Environmental Protection Agency, Tetra-through Octa-chlorinated Dioxins and Furans by Isotope Dillution (High Resolution Gas Chromatography/High Resolution Mass Spectrometry), 2010.

[25] The European Standard, Stationary Source Emissions - Determination of Mass Concentration of PCDDs/PCDFs and Dioxin-like PCBs, 2006.

[26] United States Environmental Protection Agency, Chlorinated Biphenyl Congeners in Water, Soil, Sediment, Biosolids, and Tissue by HRGC/HRMS, 2008.

[27] United States Environmental Protection Agency, Brominated Diphenyl Ethers in Water Soil,Sediment and Tissue by HRGC/HRMS, 2007.

[28] G.R. Liu, M.H. Zheng, W.B. Liu, C.Z. Wang, B. Zhang, L.R. Gao, G.J. Su, K. Xiao, P. Lv, Atmospheric emission of PCDD/Fs, PCBs, hexachlorobenzene, and pentachlorobenzene from the coking industry, Environ. Sci. Technol. 43 (2009) 9196-9201.

[29] G.R. Liu, M.H. Zheng, M.W. Cai, Z.Q. Nie, B. Zhang, W.B. Liu, B. Du, S.J. Dong, J.C. $\mathrm{Hu}, \mathrm{K}$. Xiao, Atmospheric emission of polychlorinated biphenyls from multiple industrial thermal processes, Chemosphere 90 (2013) 2453-2460.

[30] G.R. Liu, X.X. Jiang, M. Wang, S.J. Dong, M.H. Zheng, Comparison of PCDD/F levels and profiles in fly ash samples from multiple industrial thermal sources, Chemosphere 133 (2015) 68-74.

[31] J. Falandysz, M. Rose, A.R. Fernandes, Mixed poly-brominated/chlorinated biphenyls (PXBs): Widespread food and environmental contaminants, Environ. Int. 44 (2012) 118-127.

[32] M. Takekuma, K. Saito, J. Falandysz, H. Nakazawa, Ratio variation of congener profiles of PCDD/Fs and dioxin-like PCBs in human milk during lactation, Sci. Total Environ. 409 (2011) 1368-1377.
[33] G. Liu, M. Zheng, Z. Cai, Y. Wu, G. Jiang, Dioxin analysis in China, Trac-Trend Anal. Chem. 46 (2013) 178-188.

[34] G. Liu, M. Zheng, B. Du, Z. Nie, B. Zhang, W. Liu, C. Li, J. Hu, Atmospheric emission of polychlorinated naphthalenes from iron ore sintering processes, Chemosphere 89 (2012) 467-472.

[35] G. Liu, P. Lv, X. Jiang, Z. Nie, M. Zheng, Identifying iron foundries as a new source of unintentional polychlorinated naphthalenes and characterizing their emission profiles, Environ. Sci. Technol. 48 (2014) 13165-13172.

[36] R. Lega, D. Megson, C. Hartley, P. Crozier, K. MacPherson, T. Kolic, P.A. Helm, A. Myers, S.P. Bhavsar, E.J. Reiner, Congener specific determination of polychlorinated naphthalenes in sediment and biota by gas chromatography high resolution mass spectrometry, J. Chromatogr. A 1479 (2017) 169-176.

[37] G. ten Dam, I.C. Pussente, G. Scholl, G. Eppe, A. Schaechtele, S. van Leeuwen, The performance of atmospheric pressure gas chromatography-tandem mass spectrometry compared to gas chromatography-high resolution mass spectrometry for the analysis of polychlorinated dioxins and polychlorinated biphenyls in food and feed samples, J. Chromatogr. A 1477 (2016) 76-90.

[38] S. Hashimoto, Y. Takazawa, A. Fushimi, K. Tanabe, Y. Shibata, T. Ieda, N. Ochiai, H. Kanda, T. Ohura, Q. Tao, S.E. Reichenbach, Global and selective detection of organohalogens in environmental samples by comprehensive two-dimensional gas chromatography-tandem mass spectrometry and high-resolution time-of-flight mass spectrometry, J. Chromatogr. A 1218 (2011) 3799-3810.

[39] S. Hashimoto, Y. Zushi, A. Fushimi, Y. Takazawa, K. Tanabe, Y. Shibata, Selective extraction of halogenated compounds from data measured by comprehensive multidimensional gas chromatography/high resolution time-of-flight mass spectrometry for non-target analysis of environmental and biological samples, J. Chromatogr. A 1282 (2013) 183-189.

[40] L.A. Currie, Limits for qualitative detection and quantitative determination application to radiochemistry, Anal. Chem. 40 (1968) 586-593.

[41] L.L. Yu, J.D. Fassett, W.F. Guthrie, Detection limit of isotope dilution mass spectrometry, Anal. Chem. 74 (2002) 3887-3891.

[42] T. Ohura, Y. Kamiya, F. Ikemori, Local and seasonal variations in concentrations of chlorinated polycyclic aromatic hydrocarbons associated with particles in a Japanese megacity, J. Hazard. Mater. 312 (2016) 254-261.

[43] A. Kitazawa, T. Amagai, T. Ohura, Temporal trends and relationships of particulate chlorinated polycyclic aromatic hydrocarbons and their parent compounds in urban air, Environ. Sci. Technol. 40 (2006) 4592-4598.

[44] Y. Horii, G. Ok, T. Ohura, K. Kannan, Occurrence and profiles of chlorinated and brominated polycyclic aromatic hydrocarbons in waste incinerators, Environ. Sci. Technol. 42 (2008) 1904-1909. 